\title{
LA PRÁCTICA ESCOLAR DURANTE LOS PRIMEROS AÑOS DEL FRANQUISMO 1
}

DOI: http://dx.doi.org/10.1590/2236-3459/71710

\author{
Gabriel Barceló-Bauzà \\ Universidad de las Islas Baleares, Palma de Mallorca/Islas Baleares, España \\ Francisca Comas-Rubí \\ Universidad de las Islas Baleares, Palma de Mallorca/Islas Baleares, España
}

María del Mar del Pozo Andrés

Universidad de Alcalá de Henares, Alcalá de Henares/Madrid, España

$\cos 80$

\begin{abstract}
Resumen
El objetivo de este artículo es contribuir a un mejor conocimiento de la práctica escolar en los años inmediatamente posteriores a la Guerra Civil española. Estudiar esta práctica desde una perspectiva histórica requiere explorar nuevas fuentes más allá de las tradicionales, por lo que en este artículo nos basamos en una de estas posibles fuentes: las memorias pedagógicas halladas en los expedientes de oposiciones para la provisión de vacantes en enseñanza primaria del período franquista. Fruto de este análisis en este artículo se ofrece información sobre los contenidos, la metodología y los materiales utilizados en las escuelas de Baleares durante la postguerra, lo que nos permite un conocimiento más matizado de su práctica escolar. Palabras clave: historia de la escuela, cultura escolar, memorias, postguerra, Islas Baleares.
\end{abstract}

\section{A PRÁTICA ESCOLAR DURANTE OS PRIMEIROS ANOS DO FRANQUISMO}

\section{Resumo}

O objetivo deste artigo é contribuir para uma melhor compreensão da prática escolar nos anos imediatamente posteriores a Guerra Civil espanhola. Estudar esta prática desde uma perspectiva histórica requer explorar

\footnotetext{
${ }^{1}$ Este artículo se ha realizado en el marco del proyecto coordinado Miradas, a través de los subproyectos titulados "La fotografía escolar en colecciones documentales de ámbito estatal (1900-1970)", EDU201452498-C2-1-P, y "La fotografía publicada como representación de los cambios y las continuidades en la cultura escolar (1900-1970)", EDU2014-52498-C2-2-P, financiados en el Programa Estatal de Fomento de la Investigación Científica y Técnica de Excelencia, Subprograma Estatal de Generación de Conocimiento, en el marco del Plan Estatal de Investigación Científica y Técnica y de Innovación 2013-2016. Ministerio de Economía, Industria y Competitividad (AEl/Feder, UE).
} 
novas fontes além das tradicionais. Este artigo, portanto, baseia-se em uma destas possíveis fontes: as memórias pedagógicas encontradas nos registros de submissão para o preenchimento de vagas na educação primária do período franquista. $O$ resultado desta análise fornece informações sobre o conteúdo, a metodologia e os materiais utilizados nas escolas Baleares, durante o período do pós-guerra, que nos permitem uma compreensão mais diferenciado de prática escolar dos professores.

Palavras-chave: história da escola, cultura escolar, memórias, pós-guerra, llhas Baleares.

\title{
SCHOOL PRACTICE DURING THE EARLY YEARS OF FRANCO REGIME
}

\begin{abstract}
The objective of this article is to contribute to a greater understanding of the school practices that took place in the years immediately following the Spanish Civil War. Studying these practices from a historical perspective requires that unique sources, not just the traditional ones, be considered. So, in this article we focus on one of these possible sources: pedagogical reports found in the dossiers of public competitions to fill primary school vacancies under the Franco regime. The analysis carried out in this article provides information about the content, methodology, and materials used in Balearic schools during the years following the Spanish Civil War, thus giving us a more nuanced understanding of the school practices that took place during this period.

Keywords: school history, school culture, reports, postwar, Balearic Islands.
\end{abstract}

\section{LA PRATIQUE SCOLAIRE DURANT LES PREMIÈRES ANNÉES DU FRANQUISME}

\section{Résumé}

L'objectif de cet article est de contribuer à une meilleure connaissance de la pratique scolaire dans les années qui suivirent la guerre civile espagnole. Étudier cette pratique depuis une perspective historique exige d'explorer de nouvelles sources allant au-delà des sources traditionnelles, c'est pourquoi nous avons choisi de nous baser sur une de ces sources, à savoir les mémoires pédagogiques trouvées dans les dossiers concernant les concours destinés à couvrir les postes vacants dans l'enseignement primaire durant la période franquiste. L'analyse de ces mémoires nous permet d'offrir dans cet article des informations relatives aux contenus, à la méthodologie et aux matériaux utilisés dans les écoles des Baléares durant l'après-guerre, nous procurant ainsi une connaissance plus nuancée de leur pratique scolaire.

Mots-clés: histoire de l'école, culture scolaire, mémoires, après-guerre, îles Baléares. 


\section{Introducción}

a historia se debe hacer a través de testimonios o fuentes que nos acercan al objeto de estudio, pues éste ya no existe en la actualidad. Pero cuando el objeto a estudiar es la práctica escolar, la dificultad para hallar estos testimonios aumenta, ya que el tipo de fuentes que tradicionalmente se han conservado y usado para historiar el pasado de la escuela arrojan poca luz sobre esta práctica.

El desarrollo de una investigación sobre la escuela en Baleares durante la postguerra y sus prácticas nos ha llevado a explorar algunos de estos nuevos testimonios, y a localizar interesantes y poco conocidos acervos documentales para el estudio histórico de la escuela y sus prácticas en la España del siglo XX, como son las memorias pedagógicas halladas en los expedientes de oposición para la provisión de vacantes en enseñanza primaria, actualmente custodiados por el Archivo General de la Administración (A. G. A.). ${ }^{2}$ En muchas de estas memorias, inéditas salvo escasas excepciones (DEL POZO, 2013), los maestros narran cómo ha sido hasta ese momento su práctica escolar. En una época de imposiciones ideológicas y políticas sobre el sistema educativo en general, estas memorias muestran la existencia de continuidades y resistencias en la práctica escolar que reflejan la pervivencia de una cultura escolar en buena medida heredera de épocas anteriores.

El objetivo de este artículo es contribuir a un mejor conocimiento de la práctica escolar en los años inmediatamente posteriores a la Guerra Civil española, a la vez que mostrar, a través de nuestro estudio centrado en Baleares, el potencial de las memorias de oposición como fuente para conocer esta práctica, y para comprender mejor la cultura empírica de la escuela.

\section{Fundamentación teórica}

Que la escuela es una institución que crea, inventa y reproduce su propia cultura es una afirmación que pocos científicos sociales ponen en duda hoy en día. Si bien han sido varios los académicos que se han acercado a su estudio y análisis a través de múltiples acepciones (JULIÁ, 1995; ESCOLANO, 2000; VIÑAO, 2002; NÓVOA, 2003), todos ellos coinciden en señalar que la cultura escolar está compuesta de diferentes engranajes normas, teorías y prácticas - que se han ido sedimentando a lo largo del tiempo. Se puede hablar, según Escolano (2000), de tres tipos de culturas que a la vez interactúan y convergen. La cultura institucional o política ligada al entorno administrativo, que vemos reflejada en las normas y leyes que regulan el funcionamiento de la educación formal. La cultura académica o científica, relacionada con las teorías y discursos derivados del ámbito intelectual o pedagógico. Y la cultura empírica o práctica, constituida por las diferentes prácticas profesionales que han desarrollado los docentes a lo largo del tiempo.

Abordar el estudio histórico de esa cultura empírica implica el uso de diferentes

2 El Archivo General de la Administración (A.G.A.) se ubica en la ciudad de Alcalá de Henares (Madrid.
España). Creado en 1969 recoge las series documentales que la Administración General del Estado español
ha ido produciendo desde el pasado siglo XIX. Estas series, generadas por los diferentes ministerios, dan
acceso a diversa documentación relacionada con la economía, la justicia, la cultura, la educación, el
urbanismo, las obras públicas o la arquitectura. Para el caso educativo, el A.G.A. conserva, en la
denominada sección de "Educación y Ciencia", un total 13.500 unidades, entre cajas y legajos, que
contienen múltiple documentación generada por algunos de los organismos ministeriales que se han
encargado de los temas educativos en España a lo largo de la época contemporánea.

Hist. Educ. (Online)

Porto Alegre

v. 22

n. 54

jan./abr. 2018

p. $334-357$ 
registros como los testimonios orales, los egodocumentos y escrituras ordinarias memorias, cuadernos escolares, etc. -, los objetos o las fotografías. Todas ellas, fuentes que de alguna forma u otra nos permiten "observar" la escuela como si lo hiciésemos a través del ojo panóptico de un centro o de la cerradura de la puerta del aula. (ESCOLANO, 2007). Algunos autores hablan de "abrir la caja negra", en clara alusión a descubrir esa parte de la historia de la escuela, la de sus prácticas diarias y cotidianas, menos conocida y de más difícil acceso. La obra The Black Box of Schooling (BRASTER; GROSVENOR; DEL POZO, 2011) es un claro ejemplo del intento por conocer la práctica escolar en el pasado, desde diferentes perspectivas metodológicas y haciendo uso de toda clase de nuevas fuentes.

En el caso de España son diversos los estudios que han abordado, a través de diferentes testimonios, la práctica y cultura escolar del Franquismo. Sin ánimo de ser exhaustivos, podemos mencionar algunas investigaciones recientes que partiendo de diversas fuentes se han acercado al estudio de esa cultura que emerge de las prácticas diarias realizadas en el aula. Ejemplo de ello son los estudios que se centran en la manualística escolar (CASTILLEJO, 2014), los cuadernos escolares de todo tipo (MARTíN, 2010; DÁVILA; NAYA, 2015), las memorias de maestros o de alumnos de magisterio (MARTÍN, 2015; BARCELÓ; COMAS; SUREDA, 2016), o las fotografías (DEL POZO; RABAZAS, 2010; BARCELÓ, 2016; COMAS; SUREDA, 2016). Las historias de vida y testimonios orales (GUICHOT, 2009-2010), así como los objetos escolares (LÓPEZ, 2009), también son otros de los testimonios utilizados para la reconstrucción de lo fue la cultura escolar franquista.

\section{Metodología y fuentes}

Nuestra investigación sobre las prácticas en la escuela de la postguerra en Baleares es de carácter histórico-educativo, por lo que utilizamos el método histórico adaptado a nuestro campo de estudio. Nuestra hipótesis de partida se sustenta en la convicción de que las prácticas escolares se pueden observar en el pasado, aunque para ello haya que explorar nuevas fuentes que nos permitan en cierta forma asomarnos al interior de las aulas, y contemplar el quehacer cotidiano de los maestros. Partiendo de esta hipótesis, nos planteamos algunas cuestiones como: ¿qué pervivencias, rupturas o resistencias se observan en la praxis educativa durante la postguerra?, ¿hasta qué punto la cultura académica y política de la escuela de postguerra influyó en las prácticas de los maestros?, o por el contrario, ¿influyó esta práctica en la transformación de la cultura escolar del Franquismo?

Entre la información localizada para dar respuesta a estos interrogantes se encuentra la documentación relativa a las oposiciones para promoción del magisterio celebradas durante el Franquismo, custodiada por el A.G.A., y en concreto las memorias pedagógicas presentadas por los maestros. ${ }^{3}$ El grueso total de la documentación generada

\footnotetext{
${ }^{3}$ La documentación conservada referida a estas oposiciones contiene gran variedad de documentos de carácter general, como los ejercicios realizados, las puntuaciones obtenidas, las actas y composición de los tribunales evaluadores. También contiene los expedientes de cada uno de los opositores, conformados a su vez por una gran variedad de documentos como la hoja de servicios certificada - constando no tener nota desfavorable de la comisión depuradora -, el pago por derecho a examen, etc., así como las memorias sobre la labor profesional desarrollada en la escuela primaria, el concepto que merecía la escuela graduada al opositor en cuestión - llamada "memoria sobre organización escolar" -, etc.
} 
por estos concursos-oposición supone, entre cajas y legajos, más de un millar de unidades (Tabla 01).

Tabla 01 - Series documentales que dan acceso a concursos-oposición celebrados durante el Franquismo.

\begin{tabular}{|c|c|c|}
\hline \multicolumn{3}{|c|}{$\begin{array}{c}\text { Archivo General de la Administración. Sección Educación y Ciencia } \\
\text { Fondo de la Dirección General de Enseñanza Primaria }\end{array}$} \\
\hline $\begin{array}{l}\text { Series de concursos-oposiciones celebrados durante } \\
\text { el Franquismo en materia de enseñanza primaria }\end{array}$ & $\begin{array}{l}\text { Períodos que } \\
\text { engloban }\end{array}$ & Signaturas \\
\hline $\begin{array}{l}\text { Expedientes de oposiciones y concursos de maestros de } \\
\text { primera enseñanza }\end{array}$ & $1928-1975$ & $32 / 01400-32 / 01463$ \\
\hline $\begin{array}{l}\text { Expedientes de oposiciones a inspectores de enseñanza } \\
\text { primaria }\end{array}$ & $1933-1953$ & $16743-16745$ \\
\hline Expedientes de concursos de traslados & $1934-1943$ & $31 / 02891-31 / 02913$ \\
\hline Expedientes de provisiones de puestos & $1936-1958$ & $16854-17636$ \\
\hline Provisiones & $1939-1950$ & $31 / 00193-31 / 00330$ \\
\hline Expedientes de oposiciones & $1940-1944$ & $31 / 03413-31 / 03567$ \\
\hline Expedientes de oposiciones & $1941-1942$ & $31 / 02771-31 / 02890$ \\
\hline Expedientes de oposiciones & $1941-1941$ & $31 / 03126-31 / 03142$ \\
\hline Expedientes de oposiciones & $1941-1946$ & $31 / 02917-31 / 02952$ \\
\hline Expedientes de concursos de traslados & $1941-1941$ & $31 / 02979-31 / 03125$ \\
\hline Expedientes de provisiones de puestos & $1941-1963$ & $18034-18063$ \\
\hline Actas y documentos de oposiciones & 1941-1952 & $18726-18734$ \\
\hline Expedientes de provisiones de puestos & 1941-1964 & $22128-22155$ \\
\hline Excedencias de magisterio & $1943-1943$ & $31 / 02914-31 / 02914$ \\
\hline Expedientes de oposiciones & $1944-1963$ & $17877-18036$ \\
\hline Expedientes de oposiciones & $1945-1948$ & $31 / 05211-31 / 05328$ \\
\hline Expedientes de oposiciones & $1945-1945$ & $31 / 02915-31 / 02917$ \\
\hline $\begin{array}{l}\text { Solicitudes de traslados de maestros de primera } \\
\text { enseñanza }\end{array}$ & $1946-1946$ & $31 / 02664-31 / 02705$ \\
\hline Expedientes de concursos de traslados & $1946-1946$ & $31 / 02597-31 / 02624$ \\
\hline $\begin{array}{l}\text { Expedientes de concursos de traslados de maestros de } \\
\text { primera enseñanza }\end{array}$ & $1946-1946$ & $31 / 02705-31 / 02770$ \\
\hline Solicitudes de traslados de directores de grupos escolares & $1946-1946$ & $31 / 02770-31 / 02770$ \\
\hline $\begin{array}{l}\text { Expedientes de oposiciones a inspectores de enseñanza } \\
\text { primaria }\end{array}$ & $1946-1954$ & $16700-16701$ \\
\hline $\begin{array}{l}\text { Expedientes de oposiciones a inspectores de enseñanza } \\
\text { primaria }\end{array}$ & $1946-1946$ & $16712-16718$ \\
\hline Provisiones de patronatos & $1949-1962$ & $31 / 00331-31 / 00341$ \\
\hline Expedientes de oposiciones & $1950-1966$ & $18308-18356$ \\
\hline $\begin{array}{l}\text { Expedientes de oposiciones a inspectores de enseñanza } \\
\text { primaria }\end{array}$ & $1954-1963$ & $19672-19677$ \\
\hline
\end{tabular}




\begin{tabular}{l|l|l}
\hline \multicolumn{3}{c}{$\begin{array}{c}\text { Archivo General de la Administración. Sección Educación y Ciencia } \\
\text { Fondo de la Dirección General de Enseñanza Primaria }\end{array}$} \\
\hline $\begin{array}{l}\text { Series de concursos-oposiciones celebrados durante } \\
\text { el Franquismo en materia de enseñanza primaria }\end{array}$ & \multicolumn{1}{c}{$\begin{array}{c}\text { Períodos que } \\
\text { engloban }\end{array}$} & \multicolumn{1}{c}{ Signaturas } \\
\hline $\begin{array}{l}\text { Expedientes de oposiciones a inspectores de enseñanza } \\
\text { primaria }\end{array}$ & $1954-1968$ & $21789-21798$ \\
\hline Expedientes de concursos de traslados & $1957-1963$ & $18064-18307$ \\
\hline $\begin{array}{l}\text { Expedientes de oposiciones } \\
\text { Expedientes de concursos de traslados de inspectores de } \\
\text { enseñanza primaria }\end{array}$ & $1958-1964$ & $17637-17869$ \\
\hline Expedientes de oposiciones & $1958-1968$ & $21787-21789$ \\
\hline $\begin{array}{l}\text { Expedientes de concursos de traslados de inspectores de } \\
\text { enseñanza primaria }\end{array}$ & $1963-1966$ & $21792-21792$ \\
\hline $\begin{array}{l}\text { Expedientes de oposiciones a dirección de grupos } \\
\text { escolares }\end{array}$ & $1965-1965$ & $22156-22272$ \\
\hline $\begin{array}{l}\text { Expedientes de oposiciones a inspectores médico- } \\
\text { escolares }\end{array}$ & $1967-1967$ & $21818-21818$ \\
\hline $\begin{array}{l}\text { Expedientes de oposiciones a cátedras de Escuelas } \\
\text { Normales }\end{array}$ & $1967-1968$ & $21993-21999$ \\
\hline Expedientes de concursos de Escuelas Normales & $1968-1973$ & $22018-22018$ \\
\hline $\begin{array}{l}\text { Expedientes de oposiciones a cátedras de Escuelas } \\
\text { Normales }\end{array}$ & $1968-1969$ & $21717-21720$ \\
\hline Actas y documentos de oposiciones & $1970-1971$ & $22273-22342$ \\
\hline Fuente: Sección de Inormacón (A. G. A.). &
\end{tabular}

Fuente: Sección de Información (A. G. A.).

Estas series contienen documentación referida a oposiciones de ingreso en el escalafón, como de promoción. Estas últimas son las que pueden contener memorias en las que se relata la práctica escolar previa de los maestros.

A continuación presentamos una tabla en la que se recogen todas las convocatorias para la provisión de plazas vacantes durante la Dictadura (Tabla 02). En ella se ve, por años, que tipo de oposiciones y memorias se exigieron a los opositores. ${ }^{4}$

\footnotetext{
${ }^{4}$ Existen diferentes tipos de memoria, que hemos clasificado en: - Memoria tipo A: exposición de la labor profesional desarrollada en la escuela primaria y concepto que tiene el opositor sobre la organización de una escuela graduada. / - Memoria tipo B: sobre organización escolar. / - Memoria tipo B/1: organización escolar y programa para el desarrollo de un curso correspondiente al período de iniciación de escuela maternal o de párvulos. / - Memoria tipo B/2: organización escolar y programa para el desarrollo de un curso correspondiente al grado de iniciación profesional sobre cualquiera de las especialidades relativas a enseñanzas agrícolas, comercial o técnico-industrial; para opositoras también enseñanzas del hogar. / Memoria tipo B/3: didáctica, metodología o organización escolar. / - Memoria tipo C: investigación personal sobre un asunto pedagógico o sobre cuestiones que la práctica profesional haya sugerido al opositor. / Memoria tipo D: proyecto de planificación del trabajo y programa de actividades en una escuela maternal durante un curso.
} 
Tabla 02 - Relación de convocatorias para proveer plazas vacantes del magisterio durante el Franquismo.

Relación de convocatorias para proveer plazas vacantes del magisterio durante el Franquismo B. O. E. = Boletín Oficial del Estado

B. O. M. E. N. = Boletín Oficial del Ministerio de Educación Nacional * = tipología de memoria que se presenta

\begin{tabular}{|c|c|c|c|c|c|c|}
\hline Año & $\begin{array}{c}\text { Secciones } \\
\text { Graduadas } \\
\text { Anejas a las } \\
\text { del } \\
\text { Magisterio }\end{array}$ & $\begin{array}{c}\text { Direcciones } \\
\text { Graduadas } \\
\text { Anejas a las } \\
\text { del } \\
\text { Magisterio }\end{array}$ & $\begin{array}{c}\text { Escuelas de } \\
\text { poblaciones } \\
\text { de }>10.000 \\
\text { habitantes }\end{array}$ & $\begin{array}{c}\text { Direcciones } \\
\text { Escuelas } \\
\text { Graduadas }\end{array}$ & $\begin{array}{c}\text { Escuelas } \\
\text { maternales y } \\
\text { párvulos }\end{array}$ & $\begin{array}{l}\text { Ingreso al } \\
\text { Cuerpo de } \\
\text { Directores } \\
\text { Escolares }\end{array}$ \\
\hline \multicolumn{7}{|l|}{1939} \\
\hline \multicolumn{7}{|l|}{1940} \\
\hline 1941 & $\begin{array}{l}\text { B.O.E. n } 135 \\
(15 / 05 / 1941) \\
{ }^{*} \text { Memoria } \\
\text { tipo A }\end{array}$ & $\begin{array}{l}\text { B.O.E. n } 135 \\
(15 / 05 / 1941) \\
\text { * Memoria } \\
\text { tipo A }\end{array}$ & $\begin{array}{l}\text { B.O.E. no } 135 \\
(15 / 05 / 1941) \\
{ }^{*} \text { Memoria } \\
\text { tipo B }\end{array}$ & $\begin{array}{l}\text { B.O.E. no } 135 \\
(15 / 05 / 1941) \\
{ }^{*} \text { Memoria } \\
\text { tipo A }\end{array}$ & & \\
\hline \multicolumn{7}{|l|}{1942} \\
\hline 1943 & $\begin{array}{l}\text { B.O.E. } n^{\circ} 200 \\
(19 / 07 / 1943) \\
\text { Sin memoria }\end{array}$ & $\begin{array}{l}\text { B.O.E. } n^{\circ} 200 \\
(19 / 07 / 1943) \\
\text { Sin memoria }\end{array}$ & & & & \\
\hline \multicolumn{7}{|l|}{1944} \\
\hline 1945 & $\begin{array}{l}\text { B.O.E. no } 71 \\
(12 / 03 / 1945) \\
\text { Sin memoria }\end{array}$ & $\begin{array}{l}\text { B.O.E. } n^{\circ} 71 \\
(12 / 03 / 1945) \\
\text { Sin memoria }\end{array}$ & $\begin{array}{l}\text { B.O.E. } n^{\circ} 214 \\
(02 / 08 / 1945) \\
{ }^{*} \text { Memoria } \\
\text { tipo B }\end{array}$ & & & \\
\hline 1946 & $\begin{array}{l}\text { B.O.E. } n^{\circ} 164 \\
(13 / 06 / 1946) \\
\text { Sin memoria }\end{array}$ & $\begin{array}{l}\text { B.O.E. } n^{\circ} 164 \\
(13 / 06 / 1946) \\
\text { Sin memoria }\end{array}$ & & & & \\
\hline 1947 & & & $\begin{array}{l}\text { B.O.E. no } 128 \\
(08 / 05 / 1947) \\
{ }^{*} \text { Memoria } \\
\text { tipo B }\end{array}$ & & & \\
\hline 1948 & & & $\begin{array}{l}\text { B.O.E. } n^{\circ} 120 \\
(29 / 04 / 1948) \\
{ }^{*} \text { Memoria } \\
\text { tipo B }\end{array}$ & & $\begin{array}{l}\text { B.O.E. n० } 129 \\
(08 / 05 / 1948) \\
{ }^{*} \text { Memoria } \\
\text { tipo B/1 }\end{array}$ & \\
\hline 1949 & & $\begin{array}{l}\text { B.O.M.E.N. no } \\
26(27 / 06 / 1949 \\
{ }^{*} \text { Memoria } \\
\text { tipo A }\end{array}$ & & & & \\
\hline 1950 & & & $\begin{array}{l}\text { B.O.M.E.N. } \\
\text { n}^{\circ} 11 \\
(13 / 03 / 1950) \\
\text { * Memoria } \\
\text { tipo B/2 }\end{array}$ & $\begin{array}{l}\text { B.O.M.E.N. } \\
\text { n } 32^{\circ} \\
(07 / 08 / 1950) \\
\text { * Memoria } \\
\text { tipo A }\end{array}$ & $\begin{array}{l}\text { B.O.M.E.N. } \\
\text { n}^{\circ} 32 \\
(07 / 08 / 1950) \\
\text { * Memoria } \\
\text { tipo B/1 }\end{array}$ & \\
\hline
\end{tabular}




\begin{tabular}{|c|c|c|c|c|c|c|}
\hline \multicolumn{7}{|c|}{$\begin{array}{l}\text { Relación de convocatorias para proveer plazas vacantes del magisterio durante el } \\
\text { B. O. E. = Boletín Oficial del Estado } \\
\begin{aligned} \text { B. O. M. E. N. = Boletín Oficial del Ministerio de Educación Nacional } \\
{ }^{*}=\text { tipología de memoria que se presenta }\end{aligned}\end{array}$} \\
\hline Año & $\begin{array}{c}\text { Secciones } \\
\text { Graduadas } \\
\text { Anejas a las } \\
\text { del } \\
\text { Magisterio }\end{array}$ & $\begin{array}{c}\text { Direcciones } \\
\text { Graduadas } \\
\text { Anejas a las } \\
\text { del } \\
\text { Magisterio }\end{array}$ & $\begin{array}{l}\text { Escuelas de } \\
\text { poblaciones } \\
\text { de }>10.000 \\
\text { habitantes }\end{array}$ & $\begin{array}{l}\text { Direcciones } \\
\text { Escuelas } \\
\text { Graduadas }\end{array}$ & $\begin{array}{l}\text { Escuelas } \\
\text { maternales y } \\
\text { párvulos }\end{array}$ & $\begin{array}{l}\text { Ingreso al } \\
\text { Cuerpo de } \\
\text { Directores } \\
\text { Escolares }\end{array}$ \\
\hline 1950 & & & & & $\begin{array}{l}\text { B.O.M.E.N. } \\
\text { n}^{\circ} 35 \\
(28 / 08 / 1950) \\
\text { * Memoria } \\
\text { tipo B/1 }\end{array}$ & \\
\hline 1951 & $\begin{array}{l}\text { B.O.M.E.N. } \\
n^{\circ} 41 \\
(08 / 10 / 1951) \\
{ }^{*} \text { Memoria tipo } \\
\text { B }\end{array}$ & $\begin{array}{l}\text { B.O.M.E.N. } \\
\text { n }^{\circ} 41 \\
(08 / 10 / 1951) \\
{ }^{*} \text { Memoria tipo } \\
\text { C }\end{array}$ & & $\begin{array}{l}\text { B.O.M.E.N. } \\
n^{\circ} 41 \\
(08 / 10 / 1951) \\
\text { Sin memoria }\end{array}$ & $\begin{array}{l}\text { B.O.M.E.N. } \\
\text { no } 41 \\
(08 / 10 / 1951) \\
{ }^{*} \text { Memoria } \\
\text { tipo B/1 }\end{array}$ & \\
\hline 1952 & $\begin{array}{l}\text { B.O.M.E.N. } \\
\text { no } 51^{0} \\
(22 / 12 / 1952) \\
\text { * Memoria } \\
\text { tipo B }\end{array}$ & $\begin{array}{l}\text { B.O.M.E.N. } \\
\text { no } 51 \\
(22 / 12 / 1952) \\
\text { * Memoria } \\
\text { tipo C }\end{array}$ & $\begin{array}{l}\text { B.O.M.E.N. } \\
\text { n } 45 \\
(10 / 11 / 1952) \\
\text { * Memoria } \\
\text { tipo B/2 }\end{array}$ & & & \\
\hline \multirow[t]{2}{*}{1953} & \multirow{2}{*}{$\begin{array}{l}\text { B.O.M.E.N. } \\
\text { no } 71 \\
(07 / 09 / 1953) \\
\text { * Memoria } \\
\text { tipo B }\end{array}$} & \multirow{2}{*}{$\begin{array}{l}\text { B.O.M.E.N. } \\
\text { n}^{\circ} 71 \\
(07 / 09 / 1953) \\
{ }^{*} \text { Memoria } \\
\text { tipo C }\end{array}$} & \multirow{2}{*}{$\begin{array}{l}\text { B.O.M.E.N. } \\
\text { n }^{\circ} 64 \text { y } 65 \text { (13 } \\
\text { y } 17 / 08 / 1953) \\
\text { * Memoria } \\
\text { tipo B/2 }\end{array}$} & $\begin{array}{l}\text { B.O.M.E.N. } \\
n^{\circ} 4 \\
(15 / 01 / 1953) \\
\text { Sin memoria }\end{array}$ & \multirow{2}{*}{$\begin{array}{l}\text { B.O.M.E.N. } \\
\text { n }^{\circ} 64 \text { y } 65(13 \\
\text { y } 17 / 08 / 1953) \\
{ }^{*} \text { Memoria tipo } \\
\text { B/1 }\end{array}$} & \\
\hline & & & & $\begin{array}{l}\text { B.O.E. } n^{\circ} 18 \\
(18 / 01 / 1954) \\
\text { Sin memoria }\end{array}$ & & \\
\hline 1954 & $\begin{array}{l}\text { B.O.E. } n^{\circ} 275 \\
(02 / 10 / 1954) \\
{ }^{*} \text { Memoria } \\
\text { tipo B }\end{array}$ & $\begin{array}{l}\text { B.O.E. n } 275 \\
(02 / 10 / 1954) \\
{ }^{*} \text { Memoria } \\
\text { tipo C }\end{array}$ & $\begin{array}{l}\text { B.O.E. } n^{\circ} 276 \\
(03 / 10 / 1954) \\
{ }^{*} \text { Memoria } \\
\text { tipo B/2 }\end{array}$ & $\begin{array}{l}\text { B.O.E. } n^{\circ} 354 \\
(20 / 12 / 1954) \\
\text { Sin memoria }\end{array}$ & $\begin{array}{l}\text { B.O.E. n } 277 \\
(04 / 10 / 1954) \\
{ }^{*} \text { Memoria } \\
\text { tipo B/1 }\end{array}$ & \\
\hline \multirow{2}{*}{1955} & \multirow{2}{*}{$\begin{array}{l}\text { B.O.E. n } 271 \\
(28 / 09 / 1955) \\
{ }^{*} \text { Memoria } \\
\text { tipo B }\end{array}$} & \multirow{2}{*}{$\begin{array}{l}\text { B.O.E. } n^{\circ} 271 \\
(28 / 09 / 1955) \\
{ }^{*} \text { Memoria } \\
\text { tipo C }\end{array}$} & $\begin{array}{l}\text { B.O.E. } n^{\circ} 271 \\
(28 / 09 / 1955) \\
{ }^{*} \text { Memoria } \\
\text { tipo B/2 }\end{array}$ & & \multirow{2}{*}{$\begin{array}{l}\text { B.O.E. n } 271 \\
(28 / 09 / 1955) \\
{ }^{*} \text { Memoria } \\
\text { tipo B/1 }\end{array}$} & \\
\hline & & & $\begin{array}{l}\text { B.O.E. } n^{\circ} 324 \\
(20 / 11 / 1955) \\
{ }^{*} \text { Memoria tipo } \\
\text { B/2 }\end{array}$ & & & \\
\hline 1956 & $\begin{array}{l}\text { B.O.E. } n^{\circ} 358 \\
(23 / 12 / 1956) \\
\text { * Memoria } \\
\text { tipo B }\end{array}$ & & $\begin{array}{l}\text { B.O.E. } n^{\circ} 28 \\
(28 / 01 / 1957) \\
\text { * Memoria } \\
\text { tipo B/2 }\end{array}$ & $\begin{array}{l}\text { B.O.E. } n^{\circ} 4 \\
(04 / 01 / 1957) \\
\text { *Memoria tipo } \\
\text { A }\end{array}$ & $\begin{array}{l}\text { B.O.E. n } 29 \\
(29 / 01 / 1957) \\
\text { * Memoria } \\
\text { tipo B/1 }\end{array}$ & \\
\hline
\end{tabular}




\begin{tabular}{|c|c|c|c|c|c|c|}
\hline \multicolumn{7}{|c|}{$\begin{array}{l}\text { Relación de convocatorias para proveer plazas vacantes del magisterio durante el } \\
\text { B. O. E. = Boletín Oficial del Estado } \\
\begin{aligned} \text { B. O. M. E. N. = Boletín Oficial del Ministerio de Educación Nacional } \\
{ }^{*}=\text { tipología de memoria que se presenta }\end{aligned}\end{array}$} \\
\hline Año & $\begin{array}{c}\text { Secciones } \\
\text { Graduadas } \\
\text { Anejas a las } \\
\text { del } \\
\text { Magisterio }\end{array}$ & $\begin{array}{c}\text { Direcciones } \\
\text { Graduadas } \\
\text { Anejas a las } \\
\text { del } \\
\text { Magisterio }\end{array}$ & $\begin{array}{l}\text { Escuelas de } \\
\text { poblaciones } \\
\text { de }>10.000 \\
\text { habitantes }\end{array}$ & $\begin{array}{l}\text { Direcciones } \\
\text { Escuelas } \\
\text { Graduadas }\end{array}$ & $\begin{array}{l}\text { Escuelas } \\
\text { maternales y } \\
\text { párvulos }\end{array}$ & $\begin{array}{l}\text { Ingreso al } \\
\text { Cuerpo de } \\
\text { Directores } \\
\text { Escolares }\end{array}$ \\
\hline 1957 & $\begin{array}{l}\text { B.O.E. } n^{\circ} 307 \\
(09 / 12 / 1957) \\
{ }^{*} \text { Memoria } \\
\text { tipo B }\end{array}$ & & $\begin{array}{l}\text { B.O.E. } n^{\circ} 14 \\
(16 / 01 / 1958) \\
\text { * Memoria } \\
\text { tipo } B / 2\end{array}$ & $\begin{array}{l}\text { B.O.E. } n^{\circ} 276 \\
(02 / 11 / 1957) \\
{ }^{*} \text { Memoria } \\
\text { tipo A }\end{array}$ & $\begin{array}{l}\text { B.O.E. n } 311 \\
(13 / 12 / 1957) \\
{ }^{*} \text { Memoria } \\
\text { tipo B/1 }\end{array}$ & \\
\hline 1958 & $\begin{array}{l}\text { B.O.E. n } 42 \\
(18 / 02 / 1959) \\
{ }^{*} \text { Memoria } \\
\text { tipo B }\end{array}$ & $\begin{array}{l}\text { B.O.E. n० } 8 \\
(09 / 01 / 1959) \\
{ }^{*} \text { Memoria } \\
\text { tipo C }\end{array}$ & & & & \\
\hline \multirow[t]{2}{*}{1959} & & $\begin{array}{l}\text { B.O.E. } n^{\circ} 302 \\
(18 / 12 / 1959) \\
{ }^{*} \text { Memoria }\end{array}$ & $\begin{array}{l}\text { B.O.E. } n^{0} 135 \\
(06 / 06 / 1959) \\
{ }^{*} \text { Memoria } \\
\text { tipo B/3 }\end{array}$ & \multirow{2}{*}{$\begin{array}{l}\text { B.O.E. } n^{\circ} 74 \\
(27 / 03 / 1959) \\
{ }^{*} \text { Memoria } \\
\text { tipo A }\end{array}$} & \multirow{2}{*}{$\begin{array}{l}\text { B.O.E. n } 58 \\
(09 / 03 / 1959) \\
{ }^{*} \text { Memoria } \\
\text { tipo B/1 }\end{array}$} & \\
\hline & & tipo C & $\begin{array}{l}\text { B.O.E. no } 151 \\
(25 / 06 / 1959) \\
\text { Sin memoria }\end{array}$ & & & \\
\hline 1960 & $\begin{array}{l}\text { B.O.E. } n^{\circ} 28 \\
(02 / 02 / 1961) \\
\text { * Memoria } \\
\text { tipo B }\end{array}$ & & $\begin{array}{l}\text { B.O.E. n } 55 \\
(06 / 03 / 1961) \\
{ }^{*} \text { Memoria } \\
\text { tipo B/3 }\end{array}$ & $\begin{array}{l}\text { B.O.E. } n^{\circ} 53 \\
(03 / 03 / 1961) \\
{ }^{*} \text { Memoria } \\
\text { tipo A }\end{array}$ & $\begin{array}{l}\text { B.O.E. } n^{\circ} 30 \\
(04 / 02 / 1961) \\
{ }^{*} \text { Memoria } \\
\text { tipo B/1 }\end{array}$ & \\
\hline 1961 & $\begin{array}{l}\text { B.O.E. n } 21 \\
(24 / 01 / 1962) \\
{ }^{*} \text { Memoria } \\
\text { tipo B }\end{array}$ & $\begin{array}{l}\text { B.O.E. no } 19 \\
(22 / 01 / 1962) \\
\text { * Memoria } \\
\text { tipo C }\end{array}$ & $\begin{array}{l}\text { B.O.E. no } 196 \\
(17 / 08 / 1961) \\
\text { Sin memoria }\end{array}$ & & $\begin{array}{l}\text { B.O.E. n } 75 \\
(28 / 03 / 1962) \\
{ }^{*} \text { Memoria } \\
\text { tipo B/1 }\end{array}$ & \\
\hline \multirow[t]{2}{*}{1962} & & & $\begin{array}{l}\text { B.O.E. } n^{\circ} 249 \\
(17 / 10 / 1962) \\
{ }^{*} \text { Memoria } \\
\text { tipo B/3 }\end{array}$ & & & \\
\hline & & & $\begin{array}{l}\text { B.O.E. n } 259 \\
(29 / 10 / 1962) \\
\text { Sin memoria }\end{array}$ & & & \\
\hline 1963 & $\begin{array}{l}\text { B.O.E. } n^{\circ} 5 \\
(06 / 01 / 1964) \\
{ }^{*} \text { Memoria tipo } \\
\text { B }\end{array}$ & $\begin{array}{l}\text { B.O.E. n } 5 \\
(06 / 01 / 1964) \\
{ }^{*} \text { Memoria } \\
\text { tipo C }\end{array}$ & & & $\begin{array}{l}\text { B.O.E. n } 173 \\
(20 / 07 / 1963) \\
{ }^{*} \text { Memoria } \\
\text { tipo B/1 }\end{array}$ & \\
\hline 1964 & $\begin{array}{l}\text { B.O.E. n² } 296 \\
(10 / 12 / 1964) \\
\text { * Memoria } \\
\text { tipo B }\end{array}$ & $\begin{array}{l}\text { B.O.E. n } 296 \\
(10 / 12 / 1964) \\
\text { * Memoria } \\
\text { tipo C }\end{array}$ & $\begin{array}{l}\text { B.O.E. } n^{\circ} 282 \\
(24 / 11 / 1964) \\
{ }^{*} \text { Memoria } \\
\text { tipo B/3 }\end{array}$ & $\begin{array}{l}\text { B.O.E. n } 13 \\
(15 / 01 / 1965) \\
\text { * Memoria } \\
\text { tipo A }\end{array}$ & $\begin{array}{l}\text { B.O.E. n² } 287 \\
(30 / 11 / 1964) \\
{ }^{*} \text { Memoria } \\
\text { tipo B/1 }\end{array}$ & \\
\hline
\end{tabular}




\begin{tabular}{|c|c|c|c|c|c|c|}
\hline \multicolumn{7}{|c|}{$\begin{array}{l}\text { Relación de convocatorias para proveer plazas vacantes del magisterio durante el } \\
\text { B. O. E. = Boletín Oficial del Estado } \\
\begin{aligned} \text { B. O. M. E. N. = Boletín Oficial del Ministerio de Educación Nacional } \\
{ }^{*}=\text { tipología de memoria que se presenta }\end{aligned}\end{array}$} \\
\hline Año & $\begin{array}{c}\text { Secciones } \\
\text { Graduadas } \\
\text { Anejas a las } \\
\text { del } \\
\text { Magisterio }\end{array}$ & $\begin{array}{c}\text { Direcciones } \\
\text { Graduadas } \\
\text { Anejas a las } \\
\text { del } \\
\text { Magisterio }\end{array}$ & $\begin{array}{l}\text { Escuelas de } \\
\text { poblaciones } \\
\text { de }>10.000 \\
\text { habitantes }\end{array}$ & $\begin{array}{l}\text { Direcciones } \\
\text { Escuelas } \\
\text { Graduadas }\end{array}$ & $\begin{array}{l}\text { Escuelas } \\
\text { maternales y } \\
\text { párvulos }\end{array}$ & $\begin{array}{l}\text { Ingreso al } \\
\text { Cuerpo de } \\
\text { Directores } \\
\text { Escolares }\end{array}$ \\
\hline 1964 & & & $\begin{array}{l}\text { B.O.E. } n^{\circ} 4 \\
(05 / 01 / 1965) \\
\text { Sin memoria }\end{array}$ & & & \\
\hline 1965 & & & & & $\begin{array}{l}\text { B.O.E. } n^{\circ} 304 \\
(21 / 12 / 1965) \\
{ }^{*} \text { Memoria } \\
\text { tipo } B / 1\end{array}$ & \\
\hline 1966 & & & & & & $\begin{array}{l}\text { B.O.E. } n^{\circ} 265 \\
(05 / 11 / 1966) \\
{ }^{*} \text { Memoria } \\
\text { tipo A }\end{array}$ \\
\hline \multicolumn{7}{|l|}{1967} \\
\hline 1968 & & & & & $\begin{array}{l}\text { B.O.E. n } 43 \\
(19 / 02 / 1968) \\
{ }^{*} \text { Memoria } \\
\text { tipo D }\end{array}$ & \\
\hline 1969 & & & & & $\begin{array}{l}\text { B.O.E. } n^{\circ} 165 \\
(11 / 07 / 1969) \\
{ }^{*} \text { Memoria } \\
\text { tipo D }\end{array}$ & \\
\hline \multicolumn{7}{|l|}{1970} \\
\hline \multicolumn{7}{|l|}{1971} \\
\hline 1972 & & & & & $\begin{array}{l}\text { B.O.E. n } 291 \\
(05 / 12 / 1972) \\
{ }^{*} \text { Memoria } \\
\text { tipo D }\end{array}$ & \\
\hline \multicolumn{7}{|l|}{1973} \\
\hline \multicolumn{7}{|l|}{1974} \\
\hline 1975 & & & & & & \\
\hline
\end{tabular}

Fuente: elaboración propia.

Nuestra investigación se ha centrado en las oposiciones para cubrir vacantes en Baleares, a través de las cuales hemos localizado un total de 54 memorias pedagógicas, todas ellas de maestros cuya labor profesional se había desarrollado en las islas. De éstas, 39 aportan información sobre la práctica escolar en la postguerra. Las 15 restantes las presentan maestros que ingresaron en el escalafón con posterioridad, por lo que no pueden dar testimonio del período que nos interesa. 
A continuación se presenta la relación de estas oposiciones y memorias, resaltando en negrita las 39 que contienen información sobre la postguerra, y que constituyen la muestra con la que hemos realizado este estudio (Tabla 03).

Tabla 03 - Relación de convocatorias y concursantes para proveer plazas vacantes del magisterio en Baleares durante el Franquismo.

Relación de convocatorias y concursantes para proveer plazas vacantes del magisterio en Baleares durante el Franquismo

B. O. E. = Boletín Oficial del Estado

B. O. M. E. N. = Boletín Oficial del Ministerio de Educación Nacional

* Sirva la misma nota aclaratoria sobre los tipos de memoria de la Tabla 02

\begin{tabular}{|c|c|c|c|c|}
\hline Año & $\begin{array}{l}\text { Tipo de } \\
\text { oposición y } \\
\text { convocatoria }\end{array}$ & $\begin{array}{l}\text { Tipo de } \\
\text { memoria }\end{array}$ & Concursantes que presentan memoria & $\begin{array}{l}\text { Localización } \\
\text { A. G. A. } \\
\text { (Signatura) }\end{array}$ \\
\hline \multirow[t]{2}{*}{1941} & \multirow{2}{*}{$\begin{array}{l}\text { Direcciones } \\
\text { Escuelas } \\
\text { Graduadas. } \\
\text { B.O.E. } n^{\circ} 135 \\
(15 / 05 / 1941) \\
\end{array}$} & Tipo A & $\begin{array}{l}\text { Miguel Deyá Palerm; Bernardo Sintes } \\
\text { Palacios. }\end{array}$ & Caja $31 / 3127$ \\
\hline & & Tipo A & Bárbara Bernat Colom. & Caja 31/3126 \\
\hline \multirow{4}{*}{1941} & \multirow{4}{*}{$\begin{array}{l}\text { Escuelas } \\
\text { poblaciones } \\
>10.000 \\
\text { habitantes. } \\
\text { B.O.E. } n^{\circ} 135 \\
(15 / 05 / 1941)\end{array}$} & Tipo B & $\begin{array}{l}\text { Bernardo Sintes Palacios; Bernardo Vidal } \\
\text { Oliver; Manuel Piles Alegre; Melchor } \\
\text { Rosselló Simonet; Miguel Bordoy Cerdá; } \\
\text { Vicente Villalonga Sastre. }\end{array}$ & Caja 31/2866 \\
\hline & & Tipo B & $\begin{array}{l}\text { Alberto Castell Peña; Cristóbal Jiménez } \\
\text { López. }\end{array}$ & Caja 31/2937 \\
\hline & & Tipo B & María Santandreu Buñola. & Caja 31/2863 \\
\hline & & Tipo B & $\begin{array}{l}\text { Bárbara Bernat Colom; Catalina Nolla } \\
\text { Oliver. }\end{array}$ & Caja 31/2865 \\
\hline 1948 & $\begin{array}{l}\text { Escuelas } \\
\text { maternales y } \\
\text { párvulos. } \\
\text { B.O.E. n¹29 } \\
(08 / 05 / 1948)\end{array}$ & Tipo B/1 & $\begin{array}{l}\text { Caridad Segura Miró; Catalina Marroig } \\
\text { Miguel; Esperanza Rubio Ráfols; Juana } \\
\text { Vidal Isern; Margarita Mut Juan; María } \\
\text { Ferrá Figuerola; María Magdalena Riutort } \\
\text { Villalonga; Paula Torres Morey. }\end{array}$ & Caja 31/5326 \\
\hline 1949 & $\begin{array}{l}\text { Direcciones } \\
\text { Graduadas } \\
\text { Anejas } \\
\text { B.O.M.E.N. n²6 } \\
(27 / 06 / 1949)\end{array}$ & Tipo A & $\begin{array}{l}\text { Catalina Nolla Oliver; Catalina Marroig } \\
\text { Miguel; Isabel Ferretjans Sastre; María } \\
\text { Santandreu Buñola; Margarita Bordoy } \\
\text { Sansó. }\end{array}$ & Legajo 17.107 \\
\hline 1951 & $\begin{array}{l}\text { Secciones } \\
\text { Graduadas } \\
\text { Anejas } \\
\text { B.O.M.E.N. } n^{\circ} 41 \\
(08 / 10 / 1951)\end{array}$ & Tipo B & $\begin{array}{l}\text { Antonia Espases Sarmiento; Catalina } \\
\text { Muntaner; Francisca Castell Alemany; } \\
\text { Isabel Segura Cortés; Juana Mora Juliá; } \\
\text { Margarita Florit Rebassa; Margarita Tauler } \\
\text { Breas; Pilar Castro Amo. }\end{array}$ & Legajo 17.054 \\
\hline 1952 & $\begin{array}{l}\text { Secciones } \\
\text { Graduadas } \\
\text { Anejas } \\
\text { B.O.M.E.N. } n^{\circ} 51 \\
(22 / 12 / 1952)\end{array}$ & Tipo B & Inés Ferrer Isern; Margarita Florit Rebassa. & Legajo 16.979 \\
\hline
\end{tabular}


Relación de convocatorias y concursantes para proveer plazas vacantes del magisterio en Baleares durante el Franquismo

B. O. E. = Boletín Oficial del Estado

B. O. M. E. N. = Boletín Oficial del Ministerio de Educación Nacional

* Sirva la misma nota aclaratoria sobre los tipos de memoria de la Tabla 02

\begin{tabular}{|c|c|c|c|c|}
\hline Año & $\begin{array}{c}\text { Tipo de } \\
\text { oposición y } \\
\text { convocatoria }\end{array}$ & $\begin{array}{l}\text { Tipo de } \\
\text { memoria }\end{array}$ & Concursantes que presentan memoria & $\begin{array}{l}\text { Localización } \\
\text { A. G. A. } \\
\text { (Signatura) }\end{array}$ \\
\hline 1955 & $\begin{array}{l}\text { Escuelas } \\
\text { poblaciones } \\
>10.000 \\
\text { habitantes. } \\
\text { B.O.E. n³24 } \\
(20 / 11 / 1955)\end{array}$ & Tipo B/2 & $\begin{array}{l}\text { Alejandro García Jorge; Vicente María } \\
\text { Rosselló Verger. }\end{array}$ & Legajo 17.104 \\
\hline 1955 & $\begin{array}{l}\text { Secciones } \\
\text { Graduadas } \\
\text { Anejas } \\
\text { B.O.E. n²71 } \\
(28 / 09 / 1955)\end{array}$ & Tipo B & Francisca María Luisa Mortes Fabado. & Legajo 17.298 \\
\hline 1957 & $\begin{array}{l}\text { Secciones } \\
\text { Graduadas } \\
\text { Anejas } \\
\text { B.O.E. n³07 } \\
(09 / 12 / 1957)\end{array}$ & Tipo B & Inés Ferrer Isern. & Legajo 17.351 \\
\hline 1958 & $\begin{array}{l}\text { Secciones } \\
\text { Graduadas } \\
\text { Anejas } \\
\text { B.O.E. n42 } \\
(18 / 02 / 1959)\end{array}$ & Tipo B & Bernardo Amengual Pastor. & Legajo 17.353 \\
\hline 1959 & $\begin{array}{l}\text { Direcciones de } \\
\text { Escuelas } \\
\text { Graduadas. } \\
\text { B.O.E. n74 } \\
(27 / 03 / 1959)\end{array}$ & Tipo A & $\begin{array}{l}\text { Catalina Seguí Mercadal; Juana Ana } \\
\text { Amengual Fondevila. }\end{array}$ & Legajo 17.850 \\
\hline 1960 & $\begin{array}{l}\text { Escuelas } \\
\text { poblaciones } \\
>10.000 \\
\text { habitantes } \\
\text { B.O.E. n55 } \\
(06 / 03 / 1961)\end{array}$ & Tipo B/3 & $\begin{array}{l}\text { Ascensión Zamorano Real; María de las } \\
\text { Nieves Marí Marí. }\end{array}$ & Legajo 17.661 \\
\hline 1960 & $\begin{array}{l}\text { Secciones } \\
\text { Graduadas } \\
\text { Anejas } \\
\text { B.O.E. n²8 } \\
(02 / 02 / 1961)\end{array}$ & Tipo B & Matilde Tello Bosch. & Legajo 17.694 \\
\hline \multirow{2}{*}{1962} & \multirow{2}{*}{$\begin{array}{l}\text { Escuelas } \\
\text { poblaciones } \\
>10.000 \\
\text { habitantes } \\
\text { B.O.E. } n^{\circ} 249 \\
(17 / 10 / 1962)\end{array}$} & \multirow{2}{*}{ Tipo B/3 } & Gustavo Ruiz López. & Legajo 17.896 \\
\hline & & & Margarita Serra Ramón. & Legajo 17.892 \\
\hline
\end{tabular}


Relación de convocatorias y concursantes para proveer plazas vacantes del magisterio en

Baleares durante el Franquismo

B. O. E. = Boletín Oficial del Estado

B. O. M. E. N. = Boletín Oficial del Ministerio de Educación Nacional

* Sirva la misma nota aclaratoria sobre los tipos de memoria de la Tabla 02

\begin{tabular}{|c|c|c|c|c|}
\hline Año & $\begin{array}{c}\text { Tipo de } \\
\text { oposición y } \\
\text { convocatoria }\end{array}$ & $\begin{array}{l}\text { Tipo de } \\
\text { memoria }\end{array}$ & Concursantes que presentan memoria & $\begin{array}{c}\text { Localización } \\
\text { A. G. A. } \\
\text { (Signatura) }\end{array}$ \\
\hline \multirow{3}{*}{1966} & \multirow{3}{*}{$\begin{array}{l}\text { Cuerpo de } \\
\text { Directores } \\
\text { Escolares } \\
\text { B.O.E. n²65 } \\
(05 / 11 / 1966)\end{array}$} & \multirow{3}{*}{ Tipo A } & Pedro Aulí Bosch. & Caja 32/01457 \\
\hline & & & Pedro Ponseti Olives. & Caja 32/01461 \\
\hline & & & Andrés Rotger Pizá. & Caja 32/01462 \\
\hline
\end{tabular}

Fuente: elaboración propia.

Estas 39 memorias, algunas repiten autor pues los mismos maestros pudieron haberse presentado en diferentes convocatorias, presentan una extensión variable (entre diez y cien páginas mecanografiadas y manuscritas). En ellas se explica la práctica pedagógica en diferentes escuelas donde el opositor ha ejercido. Algunas acompañan el texto con dibujos, fotos $u$ otros elementos resultantes de su práctica escolar (libros de auto elaboración, cuadernos, revistas confeccionadas por los escolares, etc.).

Como principal crítica a estas fuentes, debemos destacar dos cuestiones. Su posible subjetividad, las memorias están elaboradas por los opositores con el objetivo de resaltar lo mejor de su práctica profesional y de sus conocimientos pedagógicos. La información que contienen, por tanto, tiene un grado de subjetividad a tener en cuenta para su interpretación histórica. Esta posible subjetividad, no obstante, no les resta valor como fuente, sino todo lo contrario. Una correcta interpretación de las mismas nos ha de permitir constatar no sólo las prácticas que realizaron los maestros, sino también sus opiniones y valoraciones respecto a las mismas. Qué prácticas destacan en las memorias, en qué cuestiones insisten, de cuáles no hablan, nos puede acercar a la cultura práctica de la escuela de esos años, de la que eran portadores los maestros.

Por otra parte, hay que considerar que quienes se presentaban a estos concursos de promoción no necesariamente eran representativos de la mayoría de los maestros en activo. Posiblemente constituían, por su formación y experiencia, un grupo reducido y hasta elitista del magisterio balear. Esta circunstancia debe tenerse en cuenta para no caer en generalizaciones simplistas, pero debe aprovecharse también para hacer una lectura histórica del período en cuestión mucho más matizada.

\section{La práctica escolar en la postguerra a través de las memorias pedagógicas}

Las 39 memorias que hemos analizado aportan información sobre diferentes aspectos relativos a la práctica escolar que nos permiten conocer de forma más concreta y matizada cómo se desarrollaba. Así mismo, los temas tratados en las memorias, las aparentes contradicciones, o la forma en qué se abordan, también pueden ayudar a entender una cultura escolar en plena transformación. Nos centraremos en tres cuestiones que tratan todas las memorias y que nos parecen las más ilustrativas: los contenidos, los 
métodos y los materiales.

\section{Contenidos}

El programa escolar desarrollado en los primeros años del Franquismo debía seguir lo dispuesto en la Circular del Ministerio de Educación Nacional de 8 de marzo de 1938 (B. O. E., 1938), principal disposición legislativa en materia de enseñanza primaria hasta mediados de los años cuarenta. Los maestros no contaban en ese momento con un programa más específico, por lo que fueron ellos mismos, o la dirección del centro, los encargados de elaborar los contenidos para cada una de las materias, respetando, claro está, el talante católico y tradicionalista del Régimen.

La mayoría de los opositores intentan que sus memorias reflejen su sintonía con las nuevas directrices pedagógicas, como es el caso del maestro Melchor Rosselló:

Consideramos que para una completa educación del niño español hay que cuidar estos aspectos: Educación Moral, Religiosa, Patriótica, Estética, Intelectual y Físcia.[...]. Si conseguimos un desarrollo armonico y completo de estas seis educaciones podremos decir con alegria que hemos hecho algo de provecho para con Dios y para con nuestra Patria. (ROSSELLÓ, 1941, s. p.).

Hasta qué punto éstas eran las verdaderas ideas de los maestros, o simplemente las escribían en sus memorias para agradar, es difícil de saber. En este caso, el propio maestro Rosselló, formado en el Plan Profesional de la II República, dejó testimonio personal sobre la época, siendo muy crítico con la educación impuesta por el Franquismo, por lo que deducimos que las consideraciones expresadas en la memoria de 1941 pueden responder más a la necesidad del momento que a sus verdaderas convicciones pedagógicas. (COMAS, 1997).

Aprobada la Ley de Enseñanza Primaria de 1945 (B. O. E., 1945), se contempló ya la regulación de los programas, pero no se publicaron Cuestionarios Nacionales con este fin hasta 1953. Mientras, las escuelas, como explica Bordoy, siguieron elaborando sus propios programas:

\footnotetext{
Parece ser que se preocupan de este asunto en las altas esferas de la Enseñanza Primaria; pero mientras llega esta realidad, toda dirección de graduada debe dar y darlo al comenzar el curso - un programa completo para que las maestras puedan tener un guión en su hacer cotidiano. (BORDOY, 1950, s. p.).
}

También hace alusión a ello Catalina Nolla (1950), quien diseñaba a principio de curso los cuestionarios para las diferentes asignaturas. Aunque se continuaran aplicando metodologías activas y renovadoras, los contenidos que se enseñaban, en contraposición a lo expuesto en la etapa previa a 1936, pivotaban sobre el catolicismo y el patriotismo español impuesto por la cultura política del momento. Las fotografías con las que esta maestra ilustra algunas de sus actividades después de la guerra son claramente ilustrativas de la preeminencia de estos contenidos (Figs. 01, 02 y 03). 


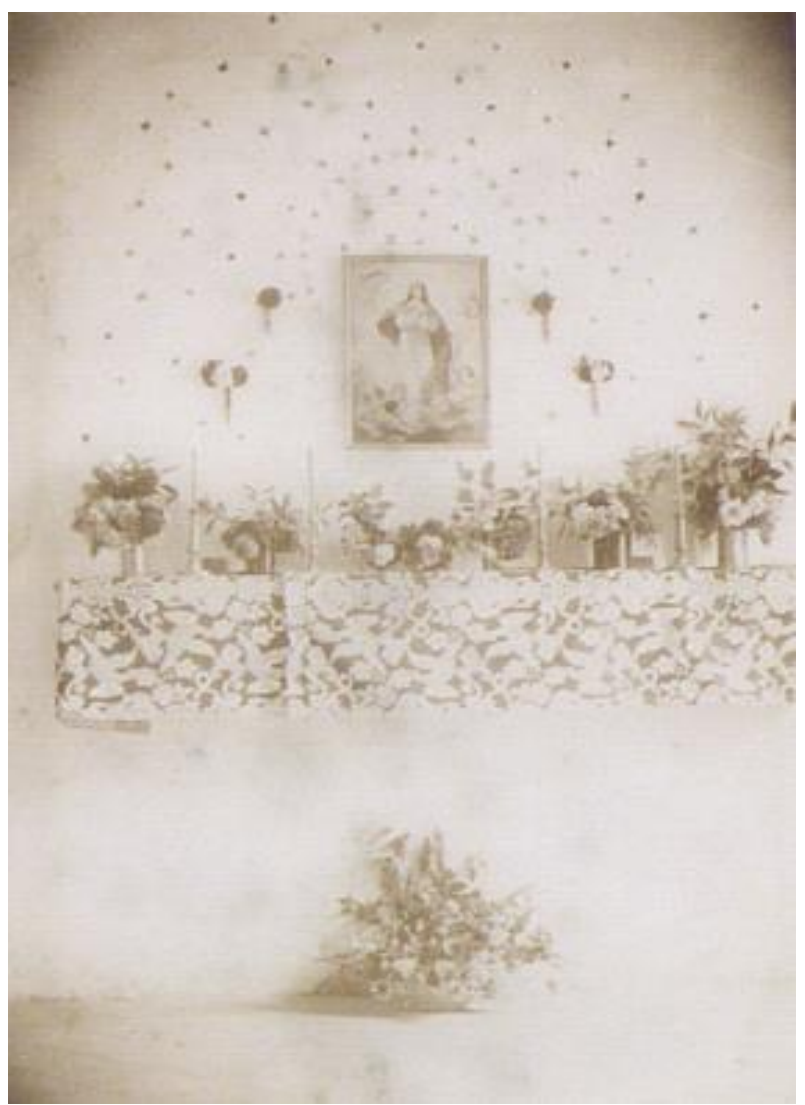

Figura 01 - Celebración del Mes de María. (NOLLA, 1950, p. 11). Fuente: A. G. A. (Sección Educación y Ciencia).

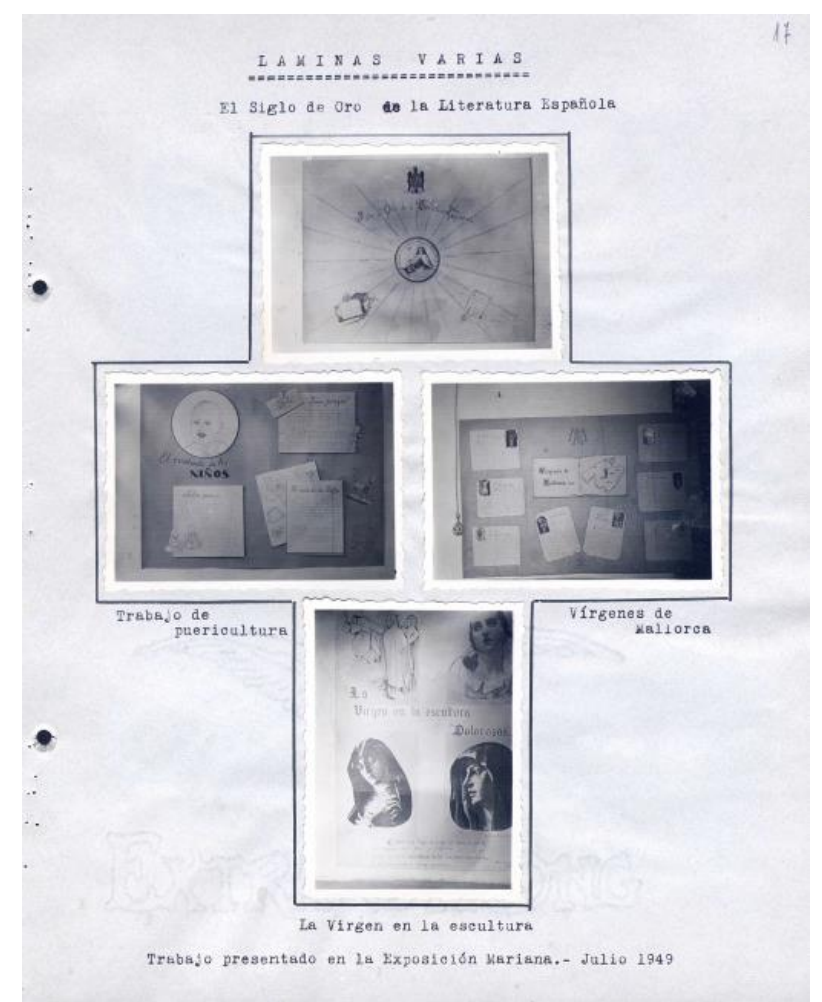

Figura 02 - Exposición mariana. (NOLLA, 1950, p. 17). Fuente: A. G. A. (Sección Educación y Ciencia). 


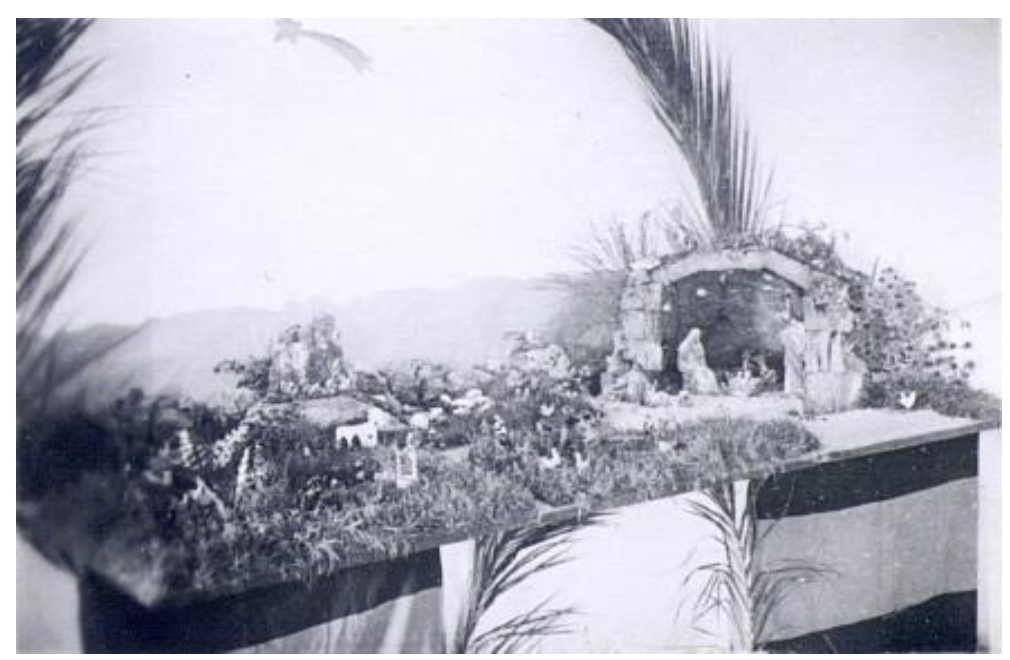

Figura 03 - Belén escolar. (NOLLA, 1950, p. 11).

Fuente: A. G. A. (Sección Educación y Ciencia).

Todas las memorias atestiguan el dominio de una cultura escolar católica y tradicionalista, de la que evidentemente nunca se menciona que sea impuesta, ni es criticada por ninguna memoria. El nacionalcatolicismo se refleja no sólo en los contenidos que se enseñan, sinó también en las prácticas, costumbres y rituales que se siguien a diario. Santandreu (1950) cuenta cómo durante su estancia en la escuela graduada de niñas de lbiza durante los primeros años de la postguerra se trabajaba el Catecismo casi todas la tardes, y que al trasladarse en el año 1941 a la segunda sección de párvulos de la Escuela Aneja Femenina, entre las prácticas más comunes que desarrollaba estaban los rezos de entrada y salida de clase, las lecciones ocasionales a raíz de las festividades religiosas y patrióticas y las explicaciones del Evangelio realizadas los sábados por la mañana. Para la educación nacionalcatólica de los párvulos, Santandreu se servía de las biografías de personajes religiosos y de aquellos que fueron protagonistas de la denominada por el Régimen "Cruzada de Liberación Nacional". La maestra Marroig (1950) cuenta cómo utilizaba la revista Consigna para la enseñanza nacionalsindicalista, mientras que a Nolla (1950) le servía para la programación de los ejercicios de educación física.

Algunas memorias destacan la creación o pervivencia de bibliotecas escolares. Nolla haciendo referencia a la escuela Santa Isabel, explica que: "En mi sección he organizado una pequeña biblioteca escolar, que se nutre de los libros comprados con los fondos formados por pequeñas cuotas que voluntariamente pagan las niñas". (1950, p. 13). En la misma línea se confeccionó la biblioteca de la escuela graduada de niños de Pedro Garau, conformada por los libros del maestro y los alumnos y las aportaciones de la rama masculina de la agrupación Acción Católica de Palma. (AULí, 1967). El maestro Deyá (1941) por su parte, también relata la existencia de una biblioteca escolar en la escuela unitaria de niños de Consell. Su confección fue posible durante la República gracias a las donaciones del ayuntamiento del pueblo y a una remesa de obras enviadas por el Patronato de Misiones Pedagógicas. No obstante, la biblioteca fue depurada durante la guerra y en 1940 sólo quedaban 18 libros.

\section{Métodos}

Tal y como consta en los trabajos de Bernat (1941a), Sintes (1941), Ferrá (1948), 
Marroig (1948, 1950), Nolla (1950), Santandreu (1950) y Castro (1951), uno de los ejercicios más habituales antes y después de la guerra son los centros de interés decrolianos, en ocasiones llamados simplemente "lecciones de cosas". Esta práctica, resultante de los movimientos de renovación pedagógica, no se interrumpió durante la guerra y postguerra. Bárbara Bernat, maestra durante la guerra en la escuela graduada de niños de Santa Catalina (Palma), relata que "En el parte diario de guerra hallábamos material más que suficiente para el desarrollo de las lecciones e inconscientemente venía a ser el centro de interés alrededor del cual giraba la labor del día". (1941a, p. 13). Catalina Marroig por su parte (1950), estando al frente de la sección de párvulos de la escuela de niñas de Algaida entre 1933 y 1946, explica haber realizado diferentes centros de interés como "el invierno", "la primavera", "el verano" o "la vivienda", práctica con la que siguió cuando se hizo cargo de la escuela unitaria de niñas del Pont d'Inca (Marratxí) entre 1946 y 1950. Por su parte, la maestra María Santandreu también asegura que utilizó los centros de interés en la escuela graduada de niñas de lbiza entre 1937 y 1941, así como en la segunda sección de párvulos de la escuela Aneja a la del Magisterio femenino de Baleares entre 1941 y 1950, en la que, como ella misma decía: "Se hace Historia a raíz de una lámina, una narración, una fiesta Nacional, una lectura, etc. La Geografía dándoles a conocer el sitio donde vivimos, el plano de la sala de clase, las calles por donde pasa el niño". (1950, p. 18). La maestra Castro por su parte, estando al frente de la escuela unitaria de niñas del pueblo menorquín de Ferreries en el curso 1947-1948, cuenta como las "lecciones de cosas" eran la principal metodología seguida para la enseñanza de las Ciencias Naturales.

También era habitual la práctica del método Montessori. Ferretjans (1950), que durante la postguerra fue maestra de párvulos en la Aneja femenina, era al parecer buena conocedora de métodos como Montessori y Decroly, habiéndolos aplicado en las diferentes escuelas en las que había ejercido. Hablando de su labor en la Aneja, explica que utilizaba el dibujo como eje sobre el cual giraba la enseñanza de la lectura y escritura. Tal y como recoge en su trabajo, el dibujo que se plasmaba en la pizarra era el que daba origen a una lección ocasional, propiciando a la vez toda una serie de ejercicios que ayudaban a la ampliación del vocabulario del párvulo (lenguaje), así como al aprendizaje de las primeras letras (escritura). Esta práctica refleja la influencia montessoriana, que usa el aprendizaje del dibujo como paso previo a la escritura. Marroig (1950) también relata que en su escuela de Algaida durante la postguerra se enseñaba la escritura a partir de las letras en lija diseñadas por Montessori y confeccionadas por ella misma. Se usaban como elemento para iniciar al párvulo en el dibujo, a la vez que servían para la educación del tacto. A continuación, y gracias a la representación mental que se habían hecho de las letras, los niños se iniciaban en la escritura.

La técnica Freinet también continúa aplicándose durante la postguerra, como lo ilustra Miguel Deyá (1941) en su memoria mediante dos imágenes, una de antes y otra de después de la guerra. En ambas fotografías vemos a sus alumnos junto a la imprenta. La primera corresponde al año 1934 (Fig. 04). En ella vemos a los alumnos de la escuela unitaria de niños de Consell junto a la imprenta utilizada para confeccionar la revista escolar Consell. Dicha revista fue publicada con periodicidad mensual entre 1934 y 1940. Realizándose un total de treinta y tres números, los seis últimos después de la guerra. (HERNÁNDEZ, 2012). En la segunda de las imágenes (Fig. 05), se ve a los alumnos de la escuela graduada de niños de Son Españolet (Palma) trabajando junto a la imprenta. En 
este caso, estaban confeccionando el primer número de la revista Letras publicado en mayo de 1941.

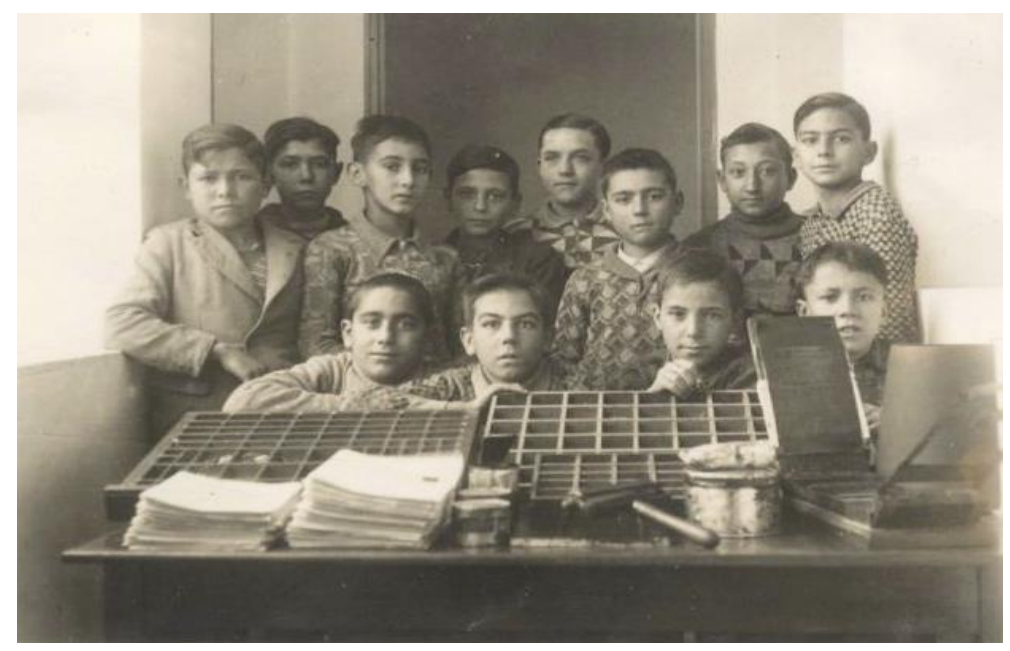

Figura 04 - Alumnos de la escuela de Consell en 1934 junto a la imprenta escolar. (DEYÁ, 1941, p. 14).

Fuente: A. G. A. (Sección Educación y Ciencia).

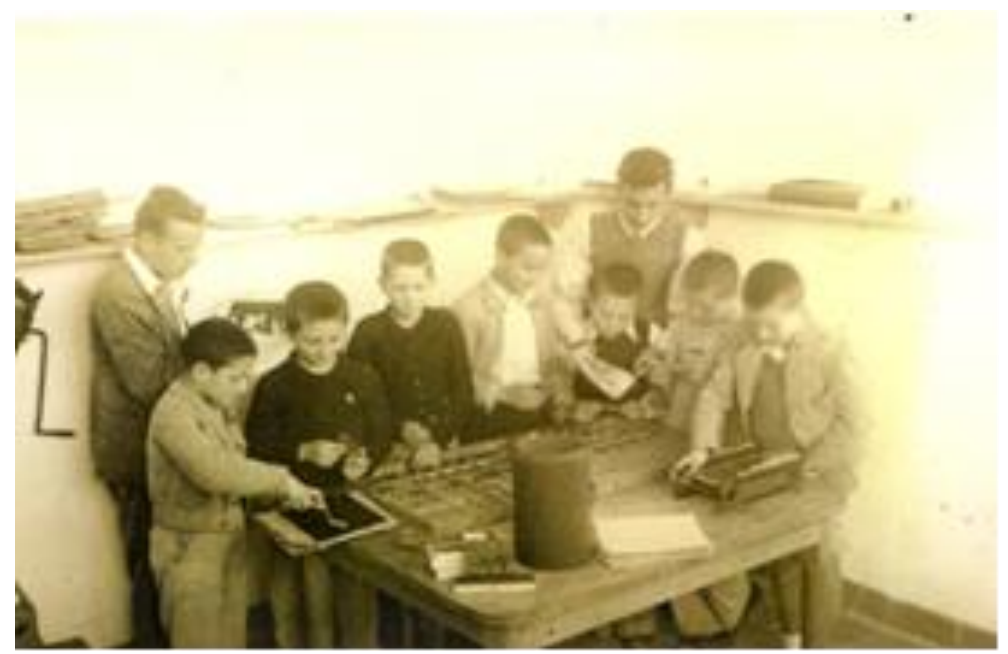

Figura 05 - Alumnos de Son Espanyolet trabajando en la imprenta escolar, curso 1940-41. (DEYÁ, 1941, p. 33).

Fuente: A. G. A. (Sección Educación y Ciencia).

La importancia del juego en el aula también se refleja en varias memorias, como la de Cristóbal Jiménez (1941) maestro en Son Servera, que relata cómo usaba el juego para favorecer el aprendizaje entre su alumnado, o Isabel Ferretjans (1950), que decía hacer del juego el principal estímulo para fomentar el aprendizaje en párvulos. Marroig (1948) enseñaba Historia mediante el juego, mientras que Santandreu (1950) relata cómo sus alumnas del parvulario de la Aneja femenina jugaban a decir Misa en clases de religión.

Otros maestros nos hablan de procedimientos activos e intuitivos como base de su enseñanza. Ejemplo de ello son las memorias de Sintes (1941), Jiménez (1941), Mut (1948), Marroig (1950), Ferretjans (1950), Santandreu (1950), Muntaner (1951), Mora (1951), Florit (1951) y Castro (1951). La maestra Santandreu, formada en el Plan Profesional de 1931, explicaba cómo su práctica siempre se basaba en la idea de que el 
niño aprende mediante la observación, por lo que evitaba en sus clases cualquier tipo de elemento que le resultase abstracto. Para enseñar los nueve primeros números utilizaba objetos que se pudieran ver in situ como piedras pequeñas, conchas, etc. También primaba la intuición en las clases de cálculo de la maestra Marroig, quien se servía de ejercicios como contar objetos, simular compra-ventas, hacer mediciones, dibujos, etc. Esta maestra también atestigua el uso de tests psicométricos, como el de Binet-Simon y el de BinetVaney, para obtener un perfil psicológico de las alumnas y ubicarlas en la sección correspondiente. Margarita Mut, maestra que regentaba la sección de párvulos de la escuela de Puigpunyent desde el año 1946, explica como su práctica era eminentemente intuitiva y basada en la educación sensorial. Ferretjans, por su parte, explica cómo echó mano de la inventiva para renovar su práctica diaria: "Inventé los campeonatos, los juegos aritméticos, las fugas de vocales [...]. Son como una gimnasia intelectual, imprimen agilidad a la mente y crean el hábito de pensar". (FERRETJANS, 1950, p. 14).

Estos ejemplos evidencian la existencia de cierta continuidad en prácticas y métodos activos renovadores extranjeros, que posiblemente todavía ocupaban un lugar privilegiado en la cultura práctica del magisterio en esos primeros años del Franquismo, a pesar de la desconfianza y animadversión que el Régimen fomentó hacia los mismos. Alguna memoria delata involuntariamente cierta confrontación entre esta práctica y la cultura escolar que se imponía desde el poder, como la de Bárbara Bernat, que reconoce aplicar centros de interés en su praxis diaria, a la vez que en su discurso teórico afirma lo siguiente:

[...] es preciso no olvidar las actividades docentes de los jesuitas, escolapios, agustinos y la de los pedagogos tan eminentes como Luis Vives, San José de Calasanz, P. Manjón si queremos que la escuela primaria española sea tal y como debe ser sin necesidad de recurrir a los extranjeros pues aunque reconozcamos su valía no tiene razón de ser. (BERNAT, 1941b, p. 2).

\section{Materiales}

En la mayoría de ocasiones eran los propios maestros los que elaboraban los materiales para la enseñanza. Melchor Rosselló aludía a la escasez de los mismos en su memoria y añadía que "[...] el Maestro que quiera lograr esta ayuda eficaz que le proporciona el material no tendrá más remedio que elaborárselo". (1941, s. p.). Marroig (1950) también cuenta en su memoria como en la sección de párvulos de la escuela de Algaida era ella misma la que construía el material pedagógico, inspirado en los objetos descritos en los métodos Montessori y Decroly, así como el utilizado en la "Maison des Petits" - Escuela Aneja del Instituto Jean-Jacques Rousseau de Ginebra -. Otros explican cómo aprendieron a elaborar estos materiales durante sus estudios en la Normal republicana, como María Santandreu:

[...] en el tercer Curso del Plan Profesional teníamos abundantes estudios teóricos y prácticos. Recuerdo que realizamos una exposición con toda clase de material confeccionado esmeradamente por nosotras, referentes a los métodos Montessori, Decroly, Proyectos, etc. (SANTANDREU, 1950, p. 2).

Algunas memorias como la de Margarita Bordoy (1950) incluyen ejemplos de los materiales de elaboración propia (Fig. 06). 


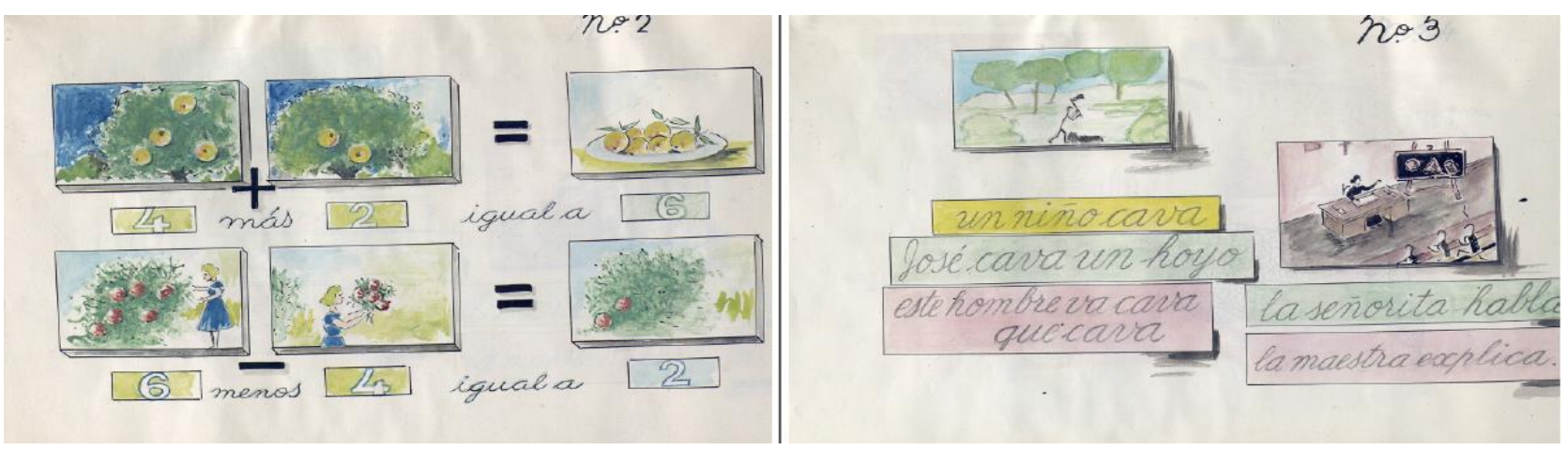

Figura 06 - Materiales para la enseñanza. (BORDOY, 1950, s. p.).

Fuente: A. G. A. (Sección Educación y Ciencia).

Los maestros Vicente Villalonga (1941), Bárbara Bernat (1941a) y Catalina Nolla (1950), por su parte, afirman que en otras ocasiones eran los propios alumnos los que creaban estos materiales: "El material lo hemos ido construyendo en la clase de trabajos manuales y como consecuencia de las explicaciones". (BERNAT, 1941a, p. 17).

Los cuadernos de los alumnos, así como los de lecciones de los maestros, serán otro de los instrumentos que articularán la práctica escolar en el aula. Miguel Bordoy (1941), explica que en su clase cada niño tenía un cuaderno en el que anotaba los ejercicios escritos, los dibujos y los problemas de cálculo. Además del cuaderno individual, había un cuaderno de rotación que servía para dejar constancia de las actividades realizadas en el aula. Por último menciona la existencia del cuaderno de preparación de lecciones en el que cada día iba anotando las observaciones de cada una de las lecciones explicadas, así como las fechas en las que se celebraba alguna festividad de significación religiosa o patriótica.

Marroig, además de su cuaderno de preparación de clases, explica que en su aula había un cuaderno de dibujo, uno de trabajos manuales y otro de rotación por grados en el que "[...] se consignaba la vida de la Escuela". (1950, p. 13). Posteriormente, durante su estancia en la unitaria de niñas del Pont d'Inca, también hizo uso de un cuaderno de Religión. De la existencia de cuadernos de Religión en las aulas también encontramos el caso de la escuela unitaria de niñas del pueblo menorquín de Es Migjorn Gran. (TAULER, 1951). María Santandreu también elogia la utilidad pedagógica de los cuadernos. Para ella, el cuaderno no podía ser un documento en limpio sin ningún tipo de enmienda. Más bien al contrario, se debía corregir a los niños en sus propios cuadernos, subrayando las faltas de ortografía, los errores de sintaxis, etc.: "La experiencia me ha demostrado que el tradicional cuaderno en limpio de uso frecuente hoy más en los colegios privados que Nacionales, no tiene razón de ser [...]". (SANTANDREU, 1950, p. 8).

\section{Conclusiones}

La primera conclusión a la que llegamos a raíz del estudio realizado es que las memorias pedagógicas guardadas en los expedientes de oposiciones para promoción del magisterio realizadas durante el Franquismo son de gran utilidad para el estudio histórico de la práctica escolar de postguerra. A pesar de la subjetividad inherente a estas memorias, 0 al hecho de que quienes opositaban para este tipo de plazas pudieran representar una minoría o una élite profesional dentro del magisterio balear, no cabe duda de que mucha de la información que contienen arroja luz sobre lo que sucedía en las escuelas y en sus 
aulas, permitiéndonos conocer matices de la práctica profesional de los maestros que otras fuentes no recogen. Por otra parte, estas memorias también pueden ser de gran ayuda para acercarnos al estudio de la cultura empírica o práctica de la escuela en esos años de profunda transformación, así como a su forma de interactuar con las otras culturas escolares (académica y política).

En cuanto a la aportación concreta de estas memorias en nuestro estudio sobre la práctica escolar en Baleares durante la postguerra, llegamos también a algunas conclusiones. Observamos, respecto a cuestiones metodológicas y prácticas, más continuidades o pervivencias que rupturas respecto a la época anterior. El saber hacer del maestro, formado en un contexto casi opuesto al del Régimen franquista, parece que es lo que dirige su labor diaria. No pasa lo mismo con los contenidos, que se adaptan a lo impuesto en ese momento. El nacionalcatolicismo rige todas las materias a nivel de contenido, y ninguna memoria se muestra crítica con ello, pero la forma de enseñar sigue siendo la misma que en el período anterior. Esto podría deberse a varios factores. Por una parte, en los años posteriores a la guerra las disposiciones sobre cómo orientar la práctica escolar hacían pocas referencias a cuestiones metodológicas, centrándose más en la orientación tradicionalista y católica de los contenidos. Por otra, los maestros opositores habían sido formados antes de la guerra, por lo que resulta lógico que aplicaran a la práctica escolar sus conocimientos metodológicos, independientemente de los contenidos a enseñar.

La observación anterior nos lleva a conclusión de que durante la postguerra convivieron e interactuaron distintas culturas escolares. Las memorias reflejan, más allá de lo que hacían los maestros en sus clases, lo que el colectivo consideraba destacable y meritorio de su práctica escolar. Los maestros hablan de sus rutinas y sus experiencias, de cómo aplican los conocimientos adquiridos a la mejora de su práctica, mostrando una cultura empírica que en muchas ocasiones se contradice con las disposiciones y los discursos oficiales de ese momento. Incluso en algunas memorias los propios maestros entran en contradicción entre los argumentos que justifican su práctica y los que a nivel teórico defienden, posiblemente por saberlos oficiales y aceptados por el Régimen. Por ejemplo, muchos opositores destacan de su práctica escolar, como mérito, el hecho que sea propia de modelos pedagógicos innovadores, racionales, intuitivos y activos, pero a la vez se manifiestan defensores del tradicionalismo y del catolicismo impuesto por el Régimen franquista.

Por otra parte, creemos que, tal y como ocurre en la actualidad, esta cultura empírica manifestada en el interior del aula durante la postguerra posiblemente depende más de la competencia profesional del docente y de las diferentes tradiciones pedagógicas que la han orientado, que de las disposiciones oficiales de cada momento. Confirmar esta conclusión requeriría continuar investigando la práctica de otros maestros de la misma época, pues ya hemos apuntado a la posibilidad de que los opositores representasen una élite dentro del magisterio balear, y no una mayoría.

Aun conscientes de sus limitaciones, creemos que este artículo aporta informaciones, reflexiones y nuevas fuentes para un conocimiento más matizado de la práctica escolar durante la postguerra, que esperamos sean de utilidad para futuras investigaciones sobre esta temática. 


\section{Referencias}

BARCELÓ, Gabriel. Photography and school culture in post-war Spain (1939-1945). A look at Majorca. Encounters in Theory and History of Education, v. 17, p. 93-118, 2016.

BARCELÓ, Gabriel; COMAS, Francisca; SUREDA, Bernat. Abriendo la caja negra: la escuela pública española de postguerra. Revista de Educación, n. 371, p. 61-82, 2016.

BOLETÍN OFICIAL DEL ESTADO. Circular a la Inspección de Primera Enseñanza y Maestros Nacionales, Municipales y Privados de la España Nacional, 8 de marzo de 1938, p. 6154-6156. 385-416.

Ley de 17 de julio de 1945 sobre Educación Primaria, 18 de julio de 1945, p.

BRASTER, Sjaak; GROSVENOR, Ian; DEL POZO, María del Mar (Eds.). The Black Box of Schooling: A Cultural History of the Classroom. Bruselas: Peter Lang, 2011.

CASTILLEJO, Emilio. Mito, legitimación y violencia simbólica en los manuales escolares de Historia del franquismo (1936-1975). Madrid: Universidad Nacional de Educación a Distancia, 2014.

COMAS, Francisca. Melcior Rosselló i Simonet, mestre. Santa Maria: Ajuntament de Santa Maria del Camí, 1997.

COMAS, Francisca; SUREDA, Bernat. Album photographique scolaire, histoire et configuration de l'identité des établissements scolaires: le cas du collège Sant Josep Obrer de Palma. Encounters in Theory and History of Education, v. 17, p. 119-140, 2016.

DÁVILA, Paulí; NAYA, Luis María. La construcción de la identidad nacional a través de los cuadernos escolares en el franquismo en el País Vasco. RIDPHE_R - Revista Iberoamericana do Patrimônio Histórico-Educativo, v. 1, n. 1, p. 7-21, 2015.

DEL POZO, María del Mar. Justa Freire o la pasión de educar. Biografía de una maestra atrapada en la historia de España (1896-1965). Barcelona: Editorial Octaedro, 2013.

DEL POZO, María del Mar; RABAZAS, Teresa. Imatges fotogràfiques i cultura escolar en el franquisme: una exploració de l'arxiu etnogràfic. Educació i Historia. Revista d'Història de l'Educació, n. 15, p. 165-194, 2010.

ESCOLANO, Agustín (Coord.). La cultura material de la escuela: en el centenario de la Junta para la Ampliación de Estudios, 1907-2007. Berlanga de Duero: Centro Internacional de la Cultura Escolar, 2007.

ESCOLANO, Agustín. Las culturas escolares del siglo XX. Encuentros y desencuentros. Revista de Educación, n. Extraordinario, p. 201-218, 2000.

GUICHOT, Virginia. La cultura escolar del franquismo a través de la historia oral.

Cuestiones Pedagógicas, n. 20, p. 215-245, 2009-2010.

HERNÁNDEZ, José Luis. Freinet en España (1926-1939). Escuela popular, historia y pedagogía. Valladolid: Castilla Ediciones, 2012.

JULIÁ, Dominique. La cultura escolar como objeto histórico. In: MENEGUS, Margarita; GONZÁLEZ, Enrique (Coords.). Historia de las universidades modernas en

Hispanoamérica. Métodos y fuentes. Ciudad de México: Universidad Autónoma Nacional de México, 1995. p. 131-153.

LÓPEZ, Ramón. Los elementos materiales como mediadores de la cultura de la escuela. 
Referencias y testimonios historiográficos. In: VILANOU, Conrad (Coord.). Doctor Buenaventura Delgado Cridado: pedagogo e historiador. Barcelona: Publicacions i Edicions de la Universitat de Barcelona, 2009, p. 161-179.

MARTíN, Bienvenido. La cultura escolar y el oficio de maestro. Educación XX1, v. 18, n. 1, p. 147-166, 2015.

. La transmisión de valores patrióticos y cívico-sociales en el franquismo. Análisis de los cuadernos de rotación. Revista de Ciencias de la Educación, Órgano del Instituto Calasanz de Ciencias de la Educación, n. 221, p. 7-32, 2010.

NÓVOA, Antonio. Textos, imágenes y recuerdos. Escritura de nuevas historias de la educación. In: POPKEWITZ, Thomas S.; FRANKLIN, Barry M.; PEREYRA, Miguel A. (Coords.). Historia cultural y educación: ensayos críticos sobre conocimiento y escolarización. Barcelona: Pomares-Corredor, 2003. p. 61-84.

VIÑAO, Antonio. Sistemas educativos, culturas escolares y reformas. Madrid: Ediciones Morata, 2002.

Referencias archivísticas. Memorias citadas. Expedientes de provisión de puestos. A. G. A. (Sección Educación y Ciencia)

AULí BOSCH, Pedro. (1967). Caja 32/01457.

BERNAT COLOM, Bárbara. (1941a). Caja 31/3126.

BERNAT COLOM, Bárbara. (1941b). Caja 31/2865.

BORDOY CERDÁ, Miguel. (1941). Caja 31/2866.

BORDOY SANSÓ, Margarita. (1950). Legajo 17.107.

CASTRO AMO, Pilar. (1951). Legajo 17.054.

DEYÁ PALERM, Miguel. (1941). Caja 31/3127.

FERRÁ FIGUEROLA, María. (1948). Caja 31/5326.

FERRETJANS SASTRE, Isabel. (1950). Legajo 17.107.

FLORIT REBASSA, Margarita. (1951). Legajo 17.054.

JIMÉNEZ LÓPEZ, Cristóbal. (1941). Caja 31/2937.

MARROIG MIGUEL, Catalina. (1948). Caja 31/5326.

MARROIG MIGUEL, Catalina. (1950). Legajo 17.107.

MORA JULIÁ, Juana. (1951). Legajo 17.054.

MUNTANER, Catalina. (1951). Legajo 17.054.

MUT JUAN, Margarita. (1948). Caja 31/5326.

NOLLA OLIVER, Catalina. (1950). Legajo 17.107.

ROSSELLÓ SIMONET, Melchor. (1941). Caja 31/2866.

SANTANDREU BUÑOLA, María. (1950). Legajo 17.107.

SINTES PALACIOS, Bernardo. (1941). Caja 31/3127.

TAULER BREAS, Margarita. (1951). Legajo 17.054.

VILLALONGA SASTRE, Vicente. (1941). Caja 31/2866 
GABRIEL BARCELÓ BAUZÀ es Doctor en Educación por la Universidad de las Islas Baleares, Profesor Ayudante del Departamento de Pedagogía y Didácticas Específicas de la Universidad de las Islas Baleares. Su tarea investigadora se ha centrado en la historia de la educación contemporánea, prestando especial atención al estudio de la práctica y cultura escolar de los primeros años de franquismo. También ha trabajado en el uso de la fotografía como fuente para la historia de la educación.

Endereço: Universidad de las Islas Baleares, Edificio Guillem Cifre de Colonya, Campus UIB - Ctra. Valldemossa, Km. 7,5 - 07122 - Palma de Mallorca - Islas Baleares - España.

E-mail: gabriel.barcelo@uib.cat

FRANCISCA COMAS RUBÍ es Doctora en Pedagogía por la Universidad de las Islas Baleares, Profesora Titular del Departamento de Pedagogía y Didácticas Específicas de la Universidad de las Islas Baleares, con una amplia trayectoria docente e investigadora. Sus líneas de investigación prioritarias han sido la formación de los sistemas educativos liberales, la renovación pedagógica, los viajes pedagógicos, y la fotografía como fuente para la historia de la educación. Sobre fotografía y educación ha dirigido varios proyectos de investigación. Endereço: Universidad de las Islas Baleares, Edificio Guillem Cifre de Colonya, Campus UIB - Ctra. Valldemossa, Km. 7,5-07122 - Palma de Mallorca - Islas Baleares - España.

E-mail: xisca.comas@uib.es

MARÍA DEL MAR DEL POZO ANDRÉS es Doctora por la Universidad Complutense de Madrid, con Premio Extraordinario de Doctorado. Catedrática de Teoría e Historia de la Educación en la Universidad de Alcalá. Sus líneas de investigación son el papel de la educación en la construcción de identidades nacionales, la enseñanza primaria en espacios urbanos, la recepción de los movimientos educativos internacionales en España, la formación inicial y permanente del profesorado, iconografía y educación, educación de las mujeres, etnografía del aula e historia del currículum.

Endereço: Universidad de Alcalá de Henares, Departamento de Ciencias de la Educación C/ de San Cirilo, s/n - 28808 - Alcalá de Henares - Madrid - España.

E-mail: mar.delpozoandres@gmail.com

Recebido em 07 de março de 2017.

Aceito em 20 de abril de 2017. 